\title{
CONHECIMENTO TÁCITO E CONHECIMENTO ESCOLAR NA FORMAÇÃO DO PROFESSOR (POR QUE DONALD SCHÖN NÃO ENTENDEU LURIA)
}

\author{
Newton Duarte*
}

\begin{abstract}
Como as coisas não se mostram ao homem diretamente tal qual são e como o homem não tem a faculdade de ver as coisas diretamente na sua essência, a humanidade faz um détour para conhecer as coisas e sua estrutura. Justamente porque tal détour é o único caminho acessível ao homem para chegar à verdade, periodicamente a humanidade tenta poupar-se o trabalho desse desvio e procura observar diretamente a essência das coisas.
\end{abstract}

(Karel Kosik, 1976, p. 21)

RESUMO: O objetivo do texto é mostrar que os estudos de Donald Schön no campo da formação profissional em geral e da formação de professores em particular pautam-se numa epistemologia que desvaloriza o conhecimento científico/teórico/acadêmico e numa pedagogia que desvaloriza o saber escolar. Nesta direção é feita uma análise crítica das idéias de Schön acerca do conhecimento tácito e do conhecimento escolar. Essa análise crítica das idéias de Schön é inserida no contexto de uma crítica aos pressupostos epistemológicos hegemônicos atualmente no campo dos estudos sobre formação de professores.

Palavras-chave: Formação de professores. Epistemologia da prática. Professor reflexivo. Conhecimento tácito. Conhecimento escolar.

Livre-docente em Psicologia da Educação, professor da Universidade Estadual Paulista "Júlio de Mesquita Filho" (UNESP, Araraquara) e bolsista de produtividade em pesquisa do CNPQ.E-mail: newton.duarte@uol.com.br

Educ. Soc., Campinas, vol. 24, n. 83, p. 601-625, agosto 2003

Disponível em <http://www.cedes.unicamp.br> 
TACIT KNOWLEDGE AND SCHOOL KNOWLEDGE IN TEACHERS' EDUCATION (WHY DONALD SCHÖN DIDN'T UNDERSTANd LURIa)

ABSTRACT: This paper defends that Donald Schön's works on professional education in general and more particularly on teachers' education are based both on an epistemology that devalues scientific knowledge and on a pedagogy that devalues school knowledge. A critical analysis of Schön's concepts of tacit knowledge (or reflectionin-action) and school knowledge is presented. This critical analysis is inserted in the context of a criticism of the currently hegemonic epistemological ideas in the field of studies on teachers' education.

Key words: Teachers' education. Epistemology of practice. Reflective practitioner. Tacit knowledge. School knowledge.

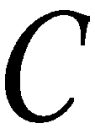

omo é sabido, os estudos realizados por Donald Schön, sobre os processos de formação do "profissional reflexivo" (Schön, 1987, 1997 e 2000), tornaram-se referência para muitas pesquisas e propostas no campo da formação de professores. No centro das proposições de Schön para a formação profissional encontra-se a distinção entre o conhecimento tácito, o qual Schön denomina também como "reflexão na ação", e o conhecimento escolar. Neste artigo pretendo problematizar os pressupostos epistemológicos e pedagógicos contidos na oposição que Schön estabelece entre esses dois tipos de conhecimento. Pretendo argumentar que Schön adota uma pedagogia que desvaloriza o conhecimento escolar e uma epistemologia que desvaloriza o conhecimento teórico/científico/acadêmico. Antes, porém, de analisar as idéias de Schön, iniciarei este artigo mostrando que a questão da desvalorização do saber teórico está presente em vários autores que se tornaram referência no campo dos estudos sobre formação de professores.

\section{A questão epistemológica no centro} do debate sobre a formação de professores

A questão epistemológica que está no centro do debate sobre formação de professores é explicitada por vários autores. Um deles é Maurice Tardif, cujo artigo publicado no ano 2000 na Revista Brasileira de Educação, periódico da Associação Nacional de Pós-Graduação e Pesquisa em Educação (ANPEd), intitulou-se "Saberes profissionais dos professores e conhecimentos universitários: elementos para uma epistemologia da prática profissional dos professores e suas con- 
seqüências em relação à formação para o magistério" (Tardif, 2000). Nesse artigo, Tardif inicia sua análise pela constatação da existência de um paradoxo na conjuntura contemporânea relativa à formação de professores: por um lado haveria um movimento no sentido da profissionalização do trabalho docente e, por outro, as profissões e a formação profissional estariam passando por um período de profunda crise. Essa crise das profissōes poderia ser resumida, segundo Tardif, em quatro pontos: crise da perícia profissional; crise de confiança na capacidade da universidade em formar bons profissionais; crise do poder profissional ou da confiança do público em relação aos profissionais e, por fim, crise da ética profissional. Nesse contexto de pressão por profissionalização do trabalho docente e, ao mesmo tempo, de crise das profissões, sobressai a questão da "epistemologia da prática":

É, portanto, nesse contexto duplamente coercitivo que a questão de uma epistemologia da prática profissional acha sua verdadeira pertinência. De fato, se admitirmos que o movimento de profissionalização é, em grande parte, uma tentativa de renovar os fundamentos epistemológicos do ofício de professor, então devemos examinar seriamente a natureza desses fundamentos e extrair daí elementos que nos permitam entrar num processo reflexivo e crítico a respeito de nossas próprias práticas como formadores e como pesquisadores. (...) chamamos de epistemologia da prática profissional o estudo do conjunto dos saberes utilizados realmente pelos professores em seu espaço de trabalho cotidiano para desempenhar sua tarefa. (Tardif, 2000, p. 10)

A partir dessa definição de epistemologia da prática profissional, Tardif desenvolve toda sua argumentação no sentido de mostrar que os cursos de formação no âmbito da universidade não têm dado conta adequadamente da formação profissional por estarem centrados no saber acadêmico, teórico, científico. A proposta de Tardif é justamente a de que as pesquisas desenvolvidas no âmbito educacional se voltem quase que inteiramente para a investigação dos saberes que os professores utilizariam em seu cotidiano profissional, frisando bem claramente que "não se devem confundir os saberes profissionais com os conhecimentos transmitidos no âmbito da formação universitária" (idem, ibid., p. 11). Esse autor é também bastante taxativo quanto às conseqüências, para a pesquisa educacional, de sua definição de epistemologia da prática profissional:

Do ponto de vista metodológico, essa definição exige o que poderíamos chamar de um distanciamento etnográfico em relação aos conhecimentos uni-

Educ. Soc., Campinas, vol. 24, n. 83, p. 601-625, agosto 2003 
versitários. Dizendo de maneira polêmica, se os pesquisadores universitários querem estudar os saberes profissionais da área de ensino, devem sair de seus laboratórios, sair de seus gabinetes na universidade, largar seus computadores, largar seus livros e os livros escritos por seus colegas que definem a natureza do ensino, os grandes valores educativos ou as leis da aprendizagem, e ir diretamente aos lugares onde os profissionais do ensino trabalham, para ver como eles pensam e falam, como trabalham na sala de aula, como transformam programas escolares para torná-los efetivos, como interagem com os pais dos alunos, com seus colegas etc. (Idem, ibid., p. 12)

Dando continuidade a seu artigo, Tardif apresenta uma caracterização dos saberes profissionais dos professores, pautado, segundo afirma, em seus próprios estudos sobre o trabalho docente e em estudos recentes realizados nos Estados Unidos, nos quais foram apresentadas sínteses de pesquisas empíricas sobre os saberes docentes. Os saberes profissionais dos professores são então caracterizados por Tardif como saberes temporais, plurais, heterogêneos, personalizados, situados e, por fim, como saberes que carregam as marcas do ser humano em conseqüência de o objeto do trabalho docente ser constituído por seres humanos (idem, ibid., p. 13-18). Esses saberes deveriam então, segundo Tardif, ocupar lugar central nos cursos de formação de professores, o que exigiria não só uma mudança curricular nesses cursos como também uma verdadeira reforma universitária, de maneira que a carreira acadêmica concedesse menos importância ao trabalho de pesquisa no campo das disciplinas acadêmicas e concedesse mais importância ao trabalho de investigação dos saberes profissionais e de sua utilização nos cursos de formação de professores. Os cursos deveriam abandonar o modelo "aplicacionista", abandonar a "lógica disciplinar" e passar a trabalhar "segundo uma lógica profissional centrada no estudo das tarefas e realidades do trabalho dos professores" (idem, p. 19). A conseqüência desse tipo de proposta para a discussão sobre os cursos de formação de professores não poderia ser diferente:

(...) é preciso quebrar a lógica disciplinar universitária nos cursos de formação profissional. Não estamos dizendo que é preciso fazer as disciplinas da formação de professores desaparecerem; dizemos somente que é preciso fazer com que contribuam de outras maneira e tirar delas, onde ainda existe, $o$ controle total na organização dos cursos. Essa tarefa é difícil porque exige uma transformação nos modelos de carreira na universidade, com todos os prestígios simbólicos e materiais que os justificam. (...) A lógica da socialização profissional (...) deve progressivamente excluir a lógica disciplinar como fundamento da formação. (Idem, ibid., p. 21; grifo meu) 
Diante dessa conclusão coerente com o artigo em seu todo, sou levado a afirmar que a discussão, entre os educadores brasileiros, sobre a instituição mais adequada para a formação de professores (se a universidade ou se outro tipo de instituição) deveria ser reformulada, pois, mesmo mantendo-se a formação de professores no âmbito da universidade, a qualidade dessa formação poderá não ser assegurada. Em outras palavras, o que estou querendo dizer é que Tardif propõe uma mudança estrutural não só nos cursos de formação como também na carreira universitária, de maneira que se releguem a um segundo plano os conhecimentos acadêmicos, científicos, teóricos. Creio ser fácil perceber que isso tem implicaçōes até mesmo em termos do número de vagas existentes nas universidades para contratação de docentes e pesquisadores no campo dos chamados fundamentos da educação. Isso para não falar da questão dos critérios adotados para análise dos pedidos de financiamento à pesquisa educacional (na ótica de Tardif, o que seria considerado uma boa pesquisa em Filosofia da Educação, por exemplo?). E para que não se diga que estou exagerando na constatação das conseqüências da proposta de Tardif, vejamos como ele mesmo encerra seu artigo, defendendo a necessidade de os professores universitários investigarem suas próprias práticas de ensino:

$\mathrm{Na}$ universidade, temos com muita freqüência a ilusão de que não temos práticas de ensino, que nós mesmos não somos profissionais do ensino ou que nossas práticas de ensino não constituem objetos legítimos para a pesquisa. Esse erro faz que evitemos os questionamentos sobre os fundamentos de nossas práticas pedagógicas, em particular nossos próprios postulados implícitos sobre a natureza dos saberes relativos ao ensino. Não problematizada, nossa própria relação com os saberes adquire, com o passar do tempo, a opacidade de um véu que turva nossa visão e restringe nossas capacidades de reação. Enfim, essa ilusão faz com que exista um abismo enorme entre nossas "teorias professadas" e nossas "teorias praticadas": elaboramos teorias do ensino e da aprendizagem que só são boas para os outros, para nossos alunos e para os professores. Então, se elas só são boas para os outros e não para nós mesmos, talvez isso seja a prova de que essas teorias não valem nada do ponto de vista da ação profissional, a começar pela nossa. (Idem, ibid., p. 21; grifo meu)

Concordo que devamos fazer constantemente a crítica aos fundamentos de nosso próprio trabalho como professores universitários. Concordo também que não estamos imunes a contradiçôes entre o que professamos e o que fazemos. Mas meu questionamento dirige-se a outro ponto: o argumento de Tardif visa justamente a solapar a va- 
lorização do conhecimento teórico, acadêmico, científico, visa a mostrar que esse tipo de conhecimento "não vale nada do ponto de vista da ação profissional". Note o leitor que Tardif não apresentou a contradição entre "teorias professadas" e "teorias praticadas" como uma exceção, mas sim como a regra. Em conseqüência, a superação desse problema não estaria na busca de coerência com a teoria professada, mas sim no seu abandono e no reconhecimento de que a verdadeira teoria é aquela que está implícita na prática.

Ao longo de todo o artigo os argumentos de Tardif vão se somando e encadeando-se a fim de conduzir à conclusão sobre a irrelevância ou até mesmo sobre o caráter prejudicial do saber científico/teórico/acadêmico tanto na formação de professores como na pesquisa educacional. Não posso deixar de identificar nessa proposição de Tardif aquele movimento caracterizado por Maria Célia Marcondes de Moraes como o "recuo da teoria" na pesquisa em educação:

A celebração do "fim da teoria" - movimento que prioriza a eficiência e a construção de um terreno consensual que toma por base a experiência imediata ou o conceito corrente de "prática reflexiva" - se faz acompanhar da promessa de uma utopia alimentada por um indigesto pragmatismo (...). Em tal utopia pragmatista, basta o "saber fazer" e a teoria é considerada perda de tempo ou especulação metafísica e, quando não, restrita a uma oratória persuasiva e fragmentária, presa à sua própria estrutura discursiva. (Moraes, 2001, p. 3)

Outro autor que também situa a questão epistemológica no centro do debate sobre formação de professores é Philippe Perrenoud. Em um livro recente, intitulado A prática reflexiva no oficio de professor: profissionalização e razão pedagógica, Perrenoud (2002) afirma que embora a universidade, por desenvolver pesquisas, pareça ser a instituição adequada para a formação do professor reflexivo, na realidade a formação desse tipo de profissional não decorre espontaneamente da existência de um ambiente de pesquisa, pois a mesma não está dirigida à formação profissional. Se a universidade deseja formar professores reflexivos então ela deveria, segundo Perrenoud (2002, p. 89-105), abandonar quatro ilusões sobre "o estado dos saberes teóricos e sua pertinência para fundar uma prática profissional": a "ilusão cientificista", a "ilusão disciplinar", a "ilusão da objetividade" e a "ilusão metodológica". A caracterização que Perrenoud faz dessas quatro ilusões aponta, no fundamental, para a mesma direção que o texto de Tardif, isto é, 
para a desvalorização do papel do conhecimento científico/teórico/acadêmico na formação do professor. O tema do papel da universidade e dos conhecimentos teóricos na formação de professores já fora tratado por Perrenoud na conferência de abertura da XXII Reunião Anual da ANPEd ocorrida em 1999, conferência essa depois publicada como artigo na Revista Brasileira de Educação, com o título "Formar professores em contextos sociais em mudança: prática reflexiva e participação crítica” (Perrenoud, 1999). Nesse artigo se lê o seguinte:

A universidade parece ser o lugar, por excelência, da reflexão e do pensamento crítico. Pode-se então ser tentado a dizer que formar os professores segundo esse paradigma é uma tarefa "natural" das universidades. Todavia, salvo em medicina, engenharia e administração, a universidade não está organizada para desenvolver competências profissionais de alto nível. Mesmo nesses domínios, Tardif mostra que os saberes disciplinares superam o desenvolvimento de competências. Isso levou algumas faculdades de medicina a operarem uma revolução, introduzindo a aprendizagem por problemas, que coloca a abordagem teórica a serviço da resolução do problema clínico desde o primeiro ano. (Idem, ibid., p. 14)

Quando essa conferência foi proferida por Perrenoud, algumas pessoas ficaram chocadas com o fato de esse autor questionar que a universidade seja o melhor local para a formação de professores. $\mathrm{Na}$ quela ocasião fiquei um tanto surpreso com a reação dessas pessoas pois o questionamento formulado por Perrenoud é uma conseqüência lógica dos pressupostos epistemológicos que dão sustentação aos estudos por ele realizados. Tais pressupostos já estavam bastante claros na coletânea de textos desse autor intitulada Práticas sociológicas, profissão docente e formação: perspectivas sociológicas (Perrenoud, 1997), cuja primeira edição em português foi lançada em 1993 com apresentação de António Nóvoa. Além dos pressupostos propriamente epistemológicos de Perrenoud, também seus pressupostos pedagógicos endereçam para a desvalorização do saber escolar. Esse autor nunca escondeu seu vínculo ao ideário escolanovista, isto é, às chamadas "pedagogias ativas" (idem, p. 71-90). Em meu artigo intitulado "As pedagogias do aprender a aprender e algumas ilusôes da assim chamada sociedade do conhecimento" (Duarte, 2001a), mostrei que o próprio Perrenoud estabelece uma linha de continuidade entre as pedagogias ativas, o construtivismo e a pedagogia das competências. Nesta perspectiva, defende que os professores transformem-se em formadores: 
Em última instância, seja qual for seu público, desejamos que todos os professores também se tornem formadores, tanto no caso de crianças quanto no de estudantes mais velhos. Lutar contra a exclusão, contra o fracasso escolar, contra a violência; desenvolver a cidadania, a autonomia, criar uma relação crítica com o saber: tudo isso exige que os professores de todos os níveis transformem-se em formadores. Sem dúvida, esta é a razão fundamental de privilegiar a postura reflexiva. (Perrenoud, 2002, p. 186-187)

Perrenoud apresenta, num quadro, as características que distinguiriam o professor do formador. Mencionarei algumas delas: o professor dá prioridade aos conhecimentos, já o formador dá prioridade às competências; o professor concebe a aprendizagem como assimilação de conhecimentos, já o formador concebe a aprendizagem como transformação da pessoa; o professor adota uma postura de sábio que compartilha seu saber, já o formador adota uma postura de treinador que orienta com firmeza uma autoformação; o professor parte de um programa, ao passo que o formador parte das necessidades, práticas e problemas encontrados (Perrenoud, 2002, p. 187). Todas essas diferenças entre o professor e o formador coadunam perfeitamente com o que caracterizei como sendo os quatro princípios valorativos contidos no lema "aprender a aprender" (Duarte, 2001b e 2001a), o que equivale a afirmar que há uma indissociável ligação, nos trabalhos de Perrenoud, entre as pedagogias do aprender a aprender (escola nova, construtivismo) e a formação do professor reflexivo. Como mostrarei mais adiante neste artigo, tal relação também está presente nos trabalhos de Donald Schön.

Essa relação entre os estudos no campo da formação de professores e a descaracterização do professor, o qual deixa de ser visto como agente da transmissão do saber escolar, também pode ser identificada no contexto educacional brasileiro. Isabel Alice Lelis (2001) aborda essa questão em artigo publicado na revista Educação \& Sociedade, intitulado "Do ensino de conteúdos aos saberes do professor: mudança de idioma pedagógico?”. Já no resumo do artigo essa questão é explicitada de forma bastante clara:

Este trabalho tem o objetivo de decifrar algumas das tendências da produção intelectual sobre formação de professores nos últimos vinte anos no Brasil, chamando a atenção para os "idiomas pedagógicos" que tiveram impacto entre os educadores. No mapeamento da literatura especializada, alguns autores/textos foram tomados como exemplares por representarem lógicas de pensamento marcantes a respeito do papel da teoria e da prática na formação docente. Do balanço efetuado, o que se verificou foi a ruptu- 
ra de um idioma pedagógico, passando-se de uma pedagogia marcadamente conteudista sob a hegemonia de uma razão teórica para uma perspectiva que aponta para uma epistemologia da prática.

O adjetivo "conteudista" tem uma clara conotação negativa, a qual é confirmada pela análise formulada ao longo do texto. Lelis considera um avanço a ruptura com uma pedagogia que valorizava a transmissão dos conteúdos pela escola e valorizava também o conhecimento teórico na formação de professores. Em substituição a essa pedagogia difundida entre os educadores brasileiros na década de 80 do século XX, teria ocorrido, na década de 90, uma mudança de foco, em grande parte influenciada pela ampla difusão dos trabalhos de autores estrangeiros no campo da formação de professores. Segundo Lelis:

(...) sob ângulos diversos, esses autores ajudaram a pensar a constituição dos saberes dos professores, em uma pauta diversa de uma pedagogia centrada no saber elaborado ao refletirem sobre os limites da formação prévia e, nela, dos conhecimentos acadêmicos na constituição do saber docente; ao afirmarem a centralidade da instituição escolar enquanto lócus de formação do magistério; ao revelarem a força da experiência escolar passada enquanto aluno no desenvolvimento da prática pedagógica; e, finalmente, ao assinalarem o caráter de improvisação a marcar o trabalho docente. (Lelis, 2001, p. 53-54)

Todo o texto de Lelis é dirigido para a análise da questão epistemológica e pedagógica que estaria no centro dessa mudança, isto é, o distanciamento com relação a uma "pedagogia centrada no saber elaborado".

Os estudos que tenho realizado sobre as relações entre o construtivismo e outros ideários pedagógicos ${ }^{1}$ me levam a afirmar que Lelis está correta quando afirma que no Brasil os estudos sobre formação de professores realizados na década de 1990 teriam significado uma mudança de enfoque pedagógico na direção de um distanciamento com relação a uma pedagogia centrada no saber escolar. Entretanto, ao contrário de Lelis, que considera esse processo um avanço, eu o considero um retrocesso. Além disso é também diferente a maneira como analiso as relaçóes entre tal processo de mudança das referências predominantes no campo da formação de professores e o contexto político-ideológico da década de 1990. Neste sentido destacarei duas questôes ausentes do trabalho de Lelis. A primeira questão é a das relações entre a difusão dessa linha de estudos sobre a formação de professores e o boom construtivista. Não foi obra do aca- 
so o fato de que o construtivismo e a pedagogia do professor reflexivo tenham sido difundidos no Brasil quase que simultaneamente. Esses dois ideários fazem parte de um universo pedagógico ao qual venho chamando de "as pedagogias do aprender a aprender". Neste sentido, do ponto de vista pedagógico, os estudos na linha do professor reflexivo surgiram na América do Norte e na Europa quase que como uma ramificação natural do tronco comum constituído pelo ideário escolanovista. A diferença reside em que o escolanovismo clássico e o construtivismo concentram seu foco de análise na aprendizagem (ou construção do conhecimento) realizada pelo aluno ao passo que os estudos sobre o professor reflexivo concentram seu foco de análise na aprendizagem (ou construção do conhecimento) realizada pelo professor. A segunda questão ausente do trabalho de Lelis é a das relações entre a epistemologia da prática e o universo ideológico neoliberal e pós-moderno. A disseminação, no Brasil, dos estudos na linha da "epistemologia da prática" e do "professor reflexivo", na década de 1990, foi impulsionada pela forte difusão da epistemologia pós-moderna e do pragmatismo neoliberal, com os quais a epistemologia da prática guarda inequívocas relações. ${ }^{2}$ A própria Lelis (2001, p. 49) tangencia esse tema quando dá a entender que "o fim do leninismo e a derrocada da União Soviética entre outros acontecimentos" teriam produzido um questionamento epistemológico com relação à filosofia da práxis, isto é, o marxismo, questionamento esse que teria problematizado a "supervalorização da teoria", o "poder da teoria na explicação e transformação do real” (idem, ibid.). A problematização do poder da teoria na explicação do real seria decorrente da constatação da "infinitude do real e dos processos de expansão e revisão do conhecimento" (idem, ibid.). Não há espaço neste artigo para me aprofundar nessa questão, mas devo assinalar que nesse momento de seu texto Lelis se aproxima dos questionamentos epistemológicos que Hayek (um dos grandes intelectuais do neoliberalismo) dirigiu ao marxismo. Não estou afirmando, de forma nenhuma, que Lelis pretenda alinhar-se com as idéias neoliberais. Em outro momento de seu texto ela se mostra preocupada com o fato de que "vivemos num momento de clara hegemonia do projeto neoliberal no campo da educação" (idem, ibid., p. 54). O que estou procurando mostrar é que inadvertidamente a autora se aproxima, em seus questionamentos epistemológicos, dos mesmos argumentos usados por Hayek. Por exemplo, a questão da "infinitude do real” é utilizada por Hayek para negar a possibilidade do conhecimento numa perspectiva de totali- 
dade. O filósofo Karel Kosik (1976, p. 41), ao tratar da concepção marxista de "totalidade concreta", mostra que Hayek estava equivocado quando criticou a epistemologia marxista, pois Hayek afirmou ser impossível o conhecimento na perspectiva da totalidade em conseqüência da impossibilidade de se conhecerem todos os fatos que compõem o real, isto é, em conseqüência daquilo que Lelis chamou de "infinitude do real". Kosik mostra que o equívoco desse argumento reside justamente em que a perspectiva marxista da totalidade não significa a pretensão de esgotar todos os fatos:

Existe uma diferença fundamental entre a opinião dos que consideram a realidade como totalidade concreta, isto é, como um todo estruturado em curso de desenvolvimento e de autocriação, e a posição dos que afirmam que o conhecimento humano pode ou não atingir a "totalidade" dos aspectos e dos fatos, isto é, das propriedades das coisas, das relações e dos processos da realidade. Como o conhecimento humano não pode jamais, por princípio, abranger todos os fatos - pois sempre é possível acrescentar fatos e aspectos ulteriores - a tese da concreticidade ou da totalidade é considerada uma mística. Na realidade, totalidade não significa todos os fatos. Totalidade significa: realidade como um todo estruturado, dialético, no qual ou do qual um fato qualquer (classe de fatos, conjunto de fatos) pode vir a ser racionalmente compreendido. (Idem, p. 35)

Aliás, a epistemologia neoliberal e a epistemologia pós-moderna convergem na abordagem que condena a perspectiva marxista de totalidade, ainda que o façam por distintas razóes teóricas e práticas. Os estudos no campo da "epistemologia da prática" e do "professor reflexivo" estão fortemente impregnados dos temas e das abordagens próprios do universo ideológico neoliberal e pós-moderno. Isso fica muito evidente, por exemplo, na leitura dos textos reunidos por António Nóvoa na coletânea intitulada Os professores e a sua formação (Nóvoa, 1997). O artigo de Thomas S. Popkewitz, nessa coletânea, aborda a relação entre profissionalização e formação de professores, sendo explícito na defesa da necessidade de se passar, na análise da questão da profissionalização do trabalho do professor, de uma "tradição iluminista" a uma "tradição pós-moderna" (Popkewitz, 1997, p. 46). Coerente com sua linha pós-estruturalista foucaultiana de análise, Popkewitz acrescenta um certo tom de ceticismo às análises da profissionalização, da formação de professores e dos currículos, apontando para as relaçóes de poder que penetrariam a educação de forma capilar, na linha da microfísica do poder. Também dentro de uma linha pós-moderna de análise mas menos preocupado com as relações 
de poder, Angel Pérez Gómez, em artigo intitulado "O pensamento prático do professor", publicado nessa mesma coletânea, deixa claras as relações entre, por um lado, o espírito anticientífico e subjetivista da epistemologia pós-moderna e, por outro lado, o espírito pragmatista típico da ideologia neoliberal, isto é, a ideologia do capitalismo contemporâneo:

$\mathrm{Na}$ vida profissional, o professor defronta-se com múltiplas situaçōes para as quais não encontra respostas pré-elaboradas e que não são suscetíveis de ser analisadas pelo processo clássico de investigação científica. Na prática profissional, o processo de diálogo com a situação deixa transparecer aspectos ocultos da realidade divergente e cria novos marcos de referência, novas formas e perspectivas de perceber e reagir. A criação e construção de uma nova realidade obrigam a ir além das regras, fatos, teorias e procedimentos conhecidos e disponíveis: "Na base dessa perspectiva, que confirma o processo de reflexão na ação do profissional, encontra-se uma concepção construtivista da realidade com que ele se defronta" (Schön). Não há realidades objetivas passíveis de serem conhecidas; as realidades criam-se e constroem-se no intercâmbio psicossocial da sala de aula. As percepções, apreciações, juízos e credos do professor são um fator decisivo na orientação desse processo de construção da realidade educativa. (Pérez Gómez, 1997, p. 110)

A afirmação de que "não há realidades objetivas passíveis de serem conhecidas" é tipicamente pós-moderna. Por outro lado, o pragmatismo presente nos argumentos de Pérez Gómez é tipicamente neoliberal. $\mathrm{Na}$ verdade não é tão fácil quanto algumas pessoas pensam separar os ideários pedagógicos afinados com a ideologia neoliberal daqueles ideários afinados com ideologias pós-modernas pretensamente "de esquerda". Em meu livro Vigotski e o "aprender a aprender": crítica às apropriaçôes neoliberais e pós-modernas da teoria vigotskiana (Duarte, 2001b) abordei essa questão no que se refere às interpretaçôes da psicologia de Vigotski, pautando-me na tese de que pós-modernismo e neoliberalismo formam duas faces de um mesmo universo ideológico, ainda que muitos autores pós-modernos se considerem "de esquerda" e vejam a si mesmos como opositores do neoliberalismo. Ambos, o pragmatismo neoliberal e o ceticismo epistemológico pós-moderno, estão unidos na veneração da subjetividade imersa no cotidiano alienado da sociedade capitalista contemporânea:

Instaurou-se a época cética e pragmática, dos textos e das interpretações que não podem mais expressar ou, até mesmo, se aproximar da realidade, mas se constituem em simples relatos ou narrativas que, presas das injunções de uma 
cultura, acabam por arrimar-se no contingente e na prática imediata - é o que se pode denominar de metafísica do presente, ou como define Jameson, uma história de presentes perpétuos (...). O ceticismo, todavia, não é apenas epistemológico, mas também ético e político. E importa para nós tanto em sua versão conservadora, enquanto peça retórica, consciente ou não, de veneração ao mercado, como igualmente em sua versão "crítica" e "radical". $\mathrm{Na}$ verdade, esses momentos, conservador e crítico, com freqüência se superpõem de tal modo que, muitas vezes, fica difícil identificá-los em sua confluência. (Moraes, 2001, p. 4)

Nesse ambiente ideológico vão aos poucos se mostrando as afinidades existentes entre vários tipos de abordagens educacionais. Por exemplo, Joe L. Kincheloe (1997) no livro intitulado $A$ formação do professor como compromisso político: mapeando o pós-moderno, defende uma determinada abordagem sobre a formação de professores, na qual os estudos de autores como Schön e Zeichner são inseridos num referencial que se nutre das contribuições do pós-modernismo de autores como Lyotard, Foucault e Derrida; do multiculturalismo de Peter Mclaren; da "pedagogia crítica” de Henry Giroux; do "construtivismo crítico" de Catherine Fosnot e de vários outros autores. Todos convergem, na abordagem defendida por Kincheloe (1997), para a formação do professor como um profissional "pós-formal".

Concluindo este item, esclareço que não foi minha intenção apresentar aqui um inventário crítico exaustivo dos estudos contemporâneos no campo da formação de professores, mas apenas mostrar que a desvalorização do conhecimento científico/teórico/acadêmico e do conhecimento escolar nos estudos de Donald Schön não é um caso isolado. Trata-se, isto sim, da tendência principal e dominante nesse terreno dos estudos educacionais. Já é o momento, então, de passar à análise das idéias de Donald Schön.

\section{As concepções de conhecimento tácito e conhecimento escolar em Donald Schön}

Inicialmente preciso esclarecer por que não dispensarei especial atenção à diferenciação feita por Schön entre "conhecer-na-ação" e "reflexão-na-ação". No livro intitulado Educando o profissional reflexivo: um novo design para o ensino e a aprendizagem, Schön (2000, p. 2936) diferencia o que ele chama de "conhecer-na-ação" e o que ele chama de "reflexão-na-ação". O "conhecer-na-ação" é mais automático, rotineiro, espontâneo, isto é, tácito. A “reflexão-na-ação” surgiria a 
partir de resultados inesperados e de surpresas produzidas pela ação. Esse processo de "reflexão-na-ação" não seria tão espontâneo quanto o "conhecer-na-ação", teria "uma função crítica, questionando a estrutura de pressupostos do conhecer-na-ação" (idem, p. 33). Entretanto, Schön ressalta que "distinção entre os processos de reflexão-naação e conhecer-na-ação pode ser sutil” (idem, p. 34) e assinala que ambos podem dispensar sua formulação em palavras:

Assim como o conhecer-na-ação, a reflexão-na-ação é um processo que podemos desenvolver sem que precisemos dizer o que estamos fazendo. Improvisadores habilidosos ficam, muitas vezes, sem palavras ou dão descrições inadequadas quando se lhes pergunta o que fazem. É claro que, sermos capazes de refletir-na-ação é diferente de sermos capazes de refletir sobre nossa reflexão-na-ação, de modo a produzir uma boa descrição verbal dela. E é ainda diferente de sermos capazes de refletir sobre a descrição resultante. (Idem, p. 35)

Se a reflexão-na-ação não exige palavras, ela se enquadra na categoria de conhecimento tácito. Para que um conhecimento deixe de ser tácito ele precisa, antes de tudo, ser expresso por meio da linguagem. Neste sentido, embora a reflexão-na-ação seja, para Schön, mais consciente que o conhecer-na-ação, a distinção entre ambos no que se refere ao grau de consciência não é tão significativa que impeça ambos de serem considerados tácitos. O próprio Schön (1987) afirma que a "reflexão-na-ação é tácita e espontânea". ${ }^{3}$ Por esta razão não darei neste artigo uma atenção especial a essa distinção entre conhecerna-ação e reflexão-na-ação. Mais importante que isso é analisar a oposição entre o conhecimento escolar e o conhecimento tácito.

Há uma relação estreita entre a pedagogia adotada por Schön e os pressupostos epistemológicos de suas teses sobre a formação de professores. Ele mesmo explicita essa relação, num texto intitulado "Formar professores como profissionais reflexivos":

(...) o que está a acontecer na educação reflete o que está a acontecer noutras áreas: uma crise de confiança no conhecimento profissional, que despoleta a busca de uma nova epistemologia da prática profissional. $\mathrm{Na}$ educação, esta crise centra-se num conflito entre o saber escolar e a reflexão-na-ação dos professores e alunos. Antes de me debruçar mais profundamente sobre esta idéia, é preciso dizer que ela nada tem de novo. Muito daquilo que acabei de referir pode ser encontrado nas obras de escritores como Leon Tolstoi, John Dewey, Alfred Schtz, Lev Vygotsky, Kurt Lewin, Jean Piaget, Ludwig Wittgenstein e David Hawkins, todos pertencendo, se bem que de formas diversas, a uma certa tradição do pensamento epistemológico e pedagógico. 
(...) O movimento crescente no sentido de uma prática reflexiva, cujas origens remontam a John Dewey, a Montessori, a Tolstoi, a Froebel, a Pestalozzi, e mesmo ao Emílio de Rosseau, encontra-se no centro de um conflito epistemológico. (Schön, 1997, p. 80 e 91)

Esse conflito epistemológico entre o conhecimento escolar e a "reflexão-na-ação" (ou conhecimento tácito) é analisado por Schön tanto no que diz respeito à formação do professor como no que diz respeito às maneiras por meio das quais a escola trabalha com o conhecimento que os alunos construiriam em seu cotidiano não-escolar.

Schön estabelece uma forte ligação entre o conhecimento tácito (conhecimento cotidiano) que o aluno traz para a sala de aula e o conhecimento também tácito que o professor constrói ao dar atenção aos processos de conhecimento e de pensamento de seus alunos por meio da reflexão-na-ação. Schön, apoiando-se no filósofo Michael Polanyi, afirma que o conhecimento tácito é:

espontâneo, intuitivo, experimental, conhecimento cotidiano, do tipo revelado pela criança que faz um bom jogo de basquetebol, (...) ou que toca ritmos complicados no tambor, apesar de não saber fazer operações aritméticas elementares. Tal como um aluno meu me dizia, falando de um seu aluno: Ele sabe fazer trocos mas não sabe somar os números. Se o professor quiser familiarizar-se com este tipo de saber, tem de lhe prestar atenção, ser curioso, ouvilo, surpreender-se, e atuar como uma espécie de detetive que procura descobrir as razões que levam as crianças a dizer certas coisas. Esse tipo de professor se esforça por ir ao encontro do aluno e entender o seu próprio processo de conhecimento, ajudando-o a articular o seu conhecimento-na-ação com o saber escolar. Este tipo de ensino é uma forma de reflexão-na-ação que exige do professor uma capacidade de individualizar, isto é, de prestar atenção a um aluno, mesmo numa turma de trinta, tendo a noção do seu grau de compreensão e das suas dificuldades. (Idem, ibid., p. 82)

Pode parecer à primeira vista que, ao referir-se ao professor que ajuda o aluno "a articular o seu conhecimento-na-ação com o saber escolar”, Schön estaria valorizando o saber escolar. Isso desautorizaria minha tese de que a pedagogia adotada por Schön desvalorizaria o saber escolar. Mas essa conclusão de que Schön valorizaria o saber escolar não se sustenta à luz de uma análise mais cuidadosa da argumentação apresentada por Schön, especialmente no que se refere à sua concepção do que seja o conhecimento escolar. Convém, de passagem, esclarecer que utilizo neste artigo indistintamente os termos "conhecimento escolar" e "saber escolar", até porque em Schön (1987) o termo utilizado é "school knowledge".

Educ. Soc., Campinas, vol. 24, n. 83, p. 601-625, agosto 2003 
Para esse autor, a uma determinada abordagem do que seja o conhecimento e o ato de conhecer corresponderia uma abordagem do que seja a aprendizagem por parte do aluno e do que seja o ensino por parte do professor. Neste, sentido Schön (1997, p. 81) contrapõe "duas formas diferentes de considerar o conhecimento, a aprendizagem e o ensino". A primeira abordagem analisada por Schön seria aquela centrada na noção de saber escolar. Vejamos como ele caracteriza o saber escolar:

Existe, primeiro que tudo, a noção de saber escolar, isto é, um tipo de conhecimento que os professores são supostos possuir e transmitir aos alunos. É uma visão dos saberes como fatos e teorias aceites, como proposições estabelecidas na seqüência de pesquisas. O saber escolar é tido como certo, significando uma profunda e quase mística crença em respostas exatas. E molecular, feito de peças isoladas, que podem ser combinadas em sistemas cada vez mais elaborados de modo a formar um conhecimento avançado. A progressão dos níveis mais elementares para os níveis mais avançados é vista como um movimento das unidades básicas para a sua combinação em estruturas complexas de conhecimento. (...) o saber escolar é categorial. Finalmente, existe a idéia muito importante de que o conhecimento molecular, certo, factual e categorial, é também privilegiado. (Schön, 1997, p. 81-82)

Não é necessária muita argúcia para perceber o tom fortemente negativo dessa caracterização do saber escolar. Compare o leitor essa passagem com aquela anteriormente citada, extraída do texto de Pérez Gómez, publicado na mesma coletânea que esse texto de Schön. Num texto o autor espanhol critica a idéia de uma realidade objetiva que possa ser conhecida pela ciência, noutro texto o autor norte-americano critica a idéia de que o saber escolar seja transmitido ao aluno como "fatos e teorias aceites". Em ambos ressalta o relativismo e o subjetivismo típicos do espírito anticientífico pósmoderno. Schön também critica o que considera ser o caráter "molecular" do saber escolar, o qual seria constituído de "peças isoladas". Assim caracterizado o saber escolar, quem sairia em sua defesa? Quem defenderia uma pedagogia na qual o professor é visto como alguém que transmite aos seus alunos peças isoladas? $\mathrm{O}$ raciocínio é bastante simples e imediato: se o saber escolar é assim como o descreve Schön, então passemos a defender uma pedagogia que não esteja baseada no saber escolar.

Como mostrei, Schön caracteriza o saber escolar como sendo categorial. Como se sabe, um conhecimento categorial trabalha com 
estruturas lógicas classificatórias do tipo: uma rosa é uma flor, uma flor é uma planta, uma planta é um ser vivo. Justamente no momento no qual Schön analisa o saber escolar como um saber categorial, ele menciona uma pesquisa realizada pelo psicólogo soviético Alexander R. Luria:

Por outro lado, o saber escolar organiza-se em categorias. Como exemplo consideremos o psicólogo russo Luria, que estudou o desenvolvimento cognitivo em camponeses no momento da coletivização da agricultura. Luria mostrava-lhes uma coleção de imagens de objetos e dizia: Associem as coisas que têm a ver umas com as outras. Uma dessas coleçôes continha uma serra, um martelo, um machado e um tronco. Quando Luria dizia Associem as coisas que têm a ver umas com as outras, os camponeses afirmavam: Bom, pode usar-se a serra para cortar a madeira para as fogueiras; pode usar-se o machado para cortar a madeira para as fogueiras; por isso é possivel associar o tronco, o machado e a serra. Então Luria retorquiu-lhes: Eu tenho um amigo que diz que todos os utensílios estão associados. A resposta dos camponeses foi pronta: $O$ seu amigo deve ter muita lenha para fazer fogueiras!. Agrupar objetos de acordo com os contextos situacionais é muito diferente do que agrupá-los numa só categoria. Neste sentido, o saber escolar é categorial. (Schön, 1997, p. 81)

Ao final deste texto voltarei a essa pesquisa de Luria para mostrar por que Donald Schön não a entendeu. Por enquanto devo prosseguir com o raciocínio de Schön. Para ele, haveria uma importante conseqüência pedagógica dessa diferença psicológica entre "agrupar objetos de acordo com seus contextos situacionais" e "agrupá-los numa só categoria". A primeira forma de agrupamento trabalharia com o que Schön chama de "representaçôes figurativas", ao passo que a segunda forma de agrupamento trabalharia com "representações formais”. O professor reflexivo seria aquele que adota uma pedagogia não pautada no saber escolar e concentra sua ação nas "representaçōes figurativas" contidas no conhecimento-na-ação dos alunos (o conhecimento cotidiano, tácito):

Tipicamente, a reflexão-na-ação de um professor implica a questão importantíssima das representaçōes múltiplas. Já mencionei o exemplo de Luria em relação à lenha. (...) Todos estes exemplos ilustram a diferença entre o que eu e Jeanne Bamberger designamos por representações "figurativas" e "formais". As figurativas implicam agrupamentos situacionais, contextualizados: as relações que se estabelecem na maior proximidade possível das experiências cotidianas. As formais implicam referência fixas, numa palavra, o saber escolar. Através da reflexão-na-ação, um professor poderá entender a compreensão figurativa que um aluno traz para a escola, compreensão que está muitas ve-

Educ. Soc., Campinas, vol. 24, n. 83, p. 601-625, agosto 2003 
zes subjacente às suas confusões e mal-entendidos em relação ao saber escolar. Quando um professor auxilia uma criança a coordenar as representaçōes figurativas e formais, não deve considerar a passagem do figurativo para o formal como um "progresso". Pelo contrário, deve ajudar a criança a associar estas diferentes estratégias de representação. (Idem, ibid., p. 83 e 85; grifo meu)

A ação pedagógica que fizesse a criança passar do conhecimento cotidiano e tácito ao conhecimento escolar não deveria, portanto, ser considerada um progresso. Haveria apenas uma "coordenação" ou uma "associação" de duas diferentes estratégias representativas. Por essa razão é que Schön critica o caráter privilegiado que tradicionalmente tem sido atribuído ao saber escolar. Assim como Schön entende não haver progresso na passagem do saber cotidiano do aluno ao saber escolar, também não haveria progresso na passagem do saber prático do professor ao saber científico e filosófico sobre a educação. A formação de professores deveria, ao invés de concentrar-se no domínio de teorias científicas, voltar-se para o saber experiencial do professor.

Apesar de mencionar a "coordenação" ou a "associação" entre as duas diferentes formas de representação, uma das quais constitui o saber escolar, Schön, em todo o seu texto, não deixa dúvidas quanto à sua visão negativa sobre o saber escolar. Ele chega mesmo a estabelecer uma ligação entre o que ele chama de sistema burocrático da escola e o saber escolar:

O sistema burocrático e regulador da escola é construído em torno do saber escolar. Uma iniciativa que ameace esta visão do conhecimento também ameaça a escola. Quando um professor tenta ouvir os seus alunos e refletirna-ação sobre o que aprende, entra inevitavelmente em conflito com a burocracia da escola. (Idem, ibid., p. 87)

Ao mesmo tempo, o saber escolar estaria também, segundo Schön, na base das reformas educacionais autoritárias que não ouvem as escolas e os professores, da mesma forma como as escolas não ouvem os seus alunos:

A estratégia de ensino baseada no saber escolar é análoga à estratégia e concepção do conhecimento implícitas na vaga atual de reformas educativas. Uma mensagem é difundida do centro para a periferia através de uma lógica de comunicação e de controle. $\mathrm{O}$ conhecimento emanado do centro é imposto na periferia, não se admitindo a sua reelaboração. De fato, quando o governo procura reformar a educação, tenta educar as escolas, do mesmo modo que estas procuram educar as crianças. (Idem, ibid., p. 82) 
Nessa linha, seria então necessário mudar: 1) a concepção de conhecimento, passando da valorização do conhecimento escolar à valorização do conhecimento tácito, cotidiano, não-científico; 2) a pedagogia, passando de uma pedagogia centrada na transmissão do saber escolar para uma pedagogia centrada na atenção aos processos pelos quais os alunos constroem seu conhecimento; 3) a formação de professores, passando de uma formação centrada no saber teórico, científico, acadêmico para uma formação centrada na prática reflexiva, centrada na reflexão-na-ação. Nesta perspectiva, o lema "aprender fazendo" da pedagogia escolanovista de inspiração deweyana deveria ser adotado tanto em relação à educação das crianças e dos adolescentes como no que diz respeito à formação profissional, incluída a formação de professores:

O que significa, então, formar um professor para que ele se torne mais capaz de refletir na e sobre a sua prática? Creio que temos mais a aprender com as tradições da educação artística que com os currículos profissionais normativos do sistema universitário de vocação profissionalizante. As instituições de formação artística (os ateliers de pintura, escultura e design, os conservatórios de música e de dança) têm longas tradições de formação profissional. Mas é evidente que muitas dessas instituições ou não estão dentro da Universidade ou vivem desconfortavelmente no seu seio. E isso por uma boa razão: baseiam-se numa concepção do saber escolar diferente da epistemologia subjacente à Universidade. As tradições "desviantes" da formação artística, bem como do treino físico e da aprendizagem profissional, contêm, no seu melhor, as características de um practicum reflexivo. Implicam um tipo de aprender fazendo, em que os alunos começam a praticar, juntamente com os que estão em idêntica situação, mesmo antes de compreenderem racionalmente o que estão a fazer. Nos ateliers de design arquitetônico, por exemplo, os alunos começam por desenhar antes de saberem o que é design. (idem, ibid., p. 88-89)

A epistemologia e a pedagogia adotadas por Schön levam, portanto, assim como acontece com outros autores no campo da formação de professores, ao tema da alegada inadequação da universidade, tal como ela se encontra estruturada, no que diz respeito à tarefa de formar profissionais, entre eles os professores. Reafirmo o que já afirmei acima: de pouco ou nada servirá a defesa da tese de que formação de professores no Brasil deva ser feita nas universidades, se não for desenvolvida uma análise crítica da desvalorização do conhecimento escolar, científico, teórico, contida nesse ideário que se tornou dominante no campo da didática e da formação de professores, isto é, esse ideário representado por autores como Schön, Tardif, Perrenoud,

Educ. Soc., Campinas, vol. 24, n. 83, p. 601-625, agosto 2003

Disponível em <http://www.cedes.unicamp.br> 
Zeichner, Nóvoa e outros. De pouco ou nada servirá mantermos a formação de professores nas universidades se o conteúdo dessa formação for maciçamente reduzido ao exercício de uma reflexão sobre os saberes profissionais, de caráter tácito, pessoal, particularizado, subjetivo etc. De pouco ou nada adiantará defendermos a necessidade de os formadores de professores serem pesquisadores em educação, se as pesquisas em educação se renderem ao "recuo da teoria". Em um texto que apresentei no Encontro Nacional de Didática e Prática de Ensino (ENDIPE), realizado em 1996 na Universidade Federal de Santa Catarina, e que foi publicado em 1998 na revista Cadernos CEDES com o título "Concepçôes afirmativas e negativas sobre o ato de ensinar" (Duarte, 1998), afirmei que o escolanovismo e o construtivismo seriam concepçōes negativas sobre o ato de ensinar. Agora estendo a mesma afirmação aos estudos na linha da "epistemologia da prática", do "professor reflexivo" e da "pedagogia das competências", pois esses estudos negam duplamente o ato de ensinar, ou seja, a transmissão do conhecimento escolar: negam que essa seja a tarefa do professor e negam que essa seja a tarefa dos formadores de professores.

Para encerrar, passarei agora a uma rápida explicação de por que afirmei no título deste artigo que Donald Schön não entendeu Luria.

\section{Por que Donald Schön não entendeu Luria}

Como já mostrei acima, Donald Schön, em certo momento de seu texto, cita uma pesquisa de Luria, objetivando exemplificar a contraposição entre o saber tácito (cotidiano) e o saber escolar. Schön cita Luria como se a pesquisa realizada por este desse apoio à tese defendida por aquele, isto é, a tese de que o conhecimento escolar, por sua natureza formal e categorial, ficaria aquém do pensamento cotidiano, ou melhor, do conhecimento tácito, o qual estaria em melhores condiçóes para lidar com a riqueza e a complexidade das situaçôes práticas. Como se pode ver, Schön defende que a escola deve deslocar seu foco de atenção do conhecimento escolar para o conhecimento tácito (cotidiano), deve deixar de considerar o saber escolar superior ao saber cotidiano e deve valorizar as formas de percepção e pensamento próprias da prática cotidiana. Esse tipo de educação escolar é que deveria, segundo Schön, constituir o fundamento da formação do professor reflexivo. É por esta razão que o saber escolar (o saber acadêmico, teórico, científico) também deveria deixar de ser o fundamento dos cursos de formação de professores. 
Acontece que Luria (1988 e 1990), ao relatar a pesquisa que planejou juntamente com Vigotski, ${ }^{4}$ é bastante explícito quanto à visão que tinha da educação escolar e de seu papel na superação das limitações próprias do pensamento cotidiano. Essa superação decorreria, entre outras coisas, justamente do caráter categorial do saber escolar. Na pesquisa realizada por Luria e sua equipe, foram realizados vários tipos de "entrevistas clínicas" com pessoas em diferentes níveis de acesso ao conhecimento escolar e vivendo em diferentes realidades sociais. Foram entrevistadas desde pessoas totalmente analfabetas que viviam e trabalhavam na zona rural, em uma situação de grande isolamento, até pessoas que já tinham um certo grau de escolarização e participavam de formas mais socializadas de trabalho. Para explicar melhor o tipo de pressuposto psicológico com o qual essa pesquisa trabalhava, Luria menciona pesquisas anteriormente realizadas por Vigotski, nas quais se mostrou que, diferentemente das crianças que agrupam objetos de maneira gráfico-funcional (relacionando os objetos a uma situação prática do cotidiano), os adolescentes agrupam os objetos de maneira categorial, isto é, taxionômica, como, por exemplo, "uma rosa é uma flor, uma flor é uma planta, uma planta é parte do mundo orgânico" (Luria, 1988, p. 48). Neste sentido, Luria afirmou o seguinte com relação aos sujeitos de sua pesquisa:

Uma vez que toda atividade é, inicialmente, fixada nas operações gráficas e práticas, acreditamos que o desenvolvimento do pensamento conceitual, taxionômico, articula-se com as operaçōes teóricas que uma criança aprende a executar na escola. Se o desenvolvimento do pensamento taxionômico depende da escolaridade formal, nós então esperaríamos ver formas taxionômicas de abstração e generalização apenas naqueles sujeitos adultos que estiveram expostos a algum tipo de escolaridade formal. Uma vez que grande parte dos sujeitos de nossas pesquisas ou não tinham freqüentado a escola ou o fizeram durante um curto período, estávamos curiosos quanto ao princípio que aplicariam para agrupar objetos encontrados em sua vida diária. (Idem, ibid.)

Quando Donald Schön citou a pesquisa de Luria, mencionou justamente o caso de um camponês analfabeto que se recusou a excluir a tora do grupo formado pelas ferramentas, isto é, uma serra, um machado e um martelo. A resposta dada por esse camponês, de que a tora só poderia ser excluída do grupo por alguém que tivesse bastante lenha, mostra que esse sujeito da pesquisa realizada por Luria apresentava um raciocínio que trabalhava com agrupamentos gráfico-funcionais e não com o pensamento categorial, taxionômico. Luria (idem, p. 50) diz que "esta tendência em contar com operações usadas na vida prática foi o 
fator controlador no caso de pessoas analfabetas e que não tinham recebido qualquer educação" (educação escolar). Os sujeitos da pesquisa que haviam alcançado um certo grau de escolarização apresentavam um pensamento não mais dominado pelo agrupamento gráfico-funcional, mas sim um pensamento capaz de trabalhar de forma categorial:

A maior parte dos sujeitos classificou os objetos não de acordo com princípios verbais e lógicos, mas de acordo com esquemas práticos. Entretanto, esse pensamento concreto não é inato, nem genericamente determinado. Resulta do analfabetismo e dos tipos rudimentares de atividade predominantes na experiência cotidiana desses sujeitos. Quando muda o padrão de vida e se ampliam as dimensões da própria experiência, quando eles aprendem a ler e a escrever, a ser parte de uma cultura mais avançada, esta maior complexidade de sua atividade estimula novas idéias. Tais modificaçôes, por sua vez, ocasionam uma reorganização radical de seus hábitos de pensamento, de modo que eles aprendem a usar e a compreender o valor de procedimentos teóricos que anteriormente pareciam irrelevantes. (Luria, 1990, p. 106-107)

Então a pergunta é: como Luria avaliava o fato de que o contexto social da vida das pessoas possa determinar que o pensamento se limite a operar de forma presa às situações cotidianas? Eis a resposta:

Se as pessoas agrupam os objetos e definem palavras com base em experiências práticas, poder-se-ia esperar que a conclusão que tiram de uma premissa dada em um problema lógico dependeria também de sua experiência prática imediata. Isso dificultaria, e talvez até tornasse impossível, a aquisição de um novo conhecimento, de maneira discursiva e lógico-verbal. Tal mudança representaria a transição da consciência sensivel para a racional, fenômeno que os autores marxistas clássicos consideram um dos mais importantes da história humana. (Luria, 1988, p. 52-53; grifo meu)

Luria entendia, portanto, que pensamento abstrato, teórico, categorial, o qual se desenvolveria a partir da educação escolar, seria superior ao pensamento gráfico-funcional:

O pensamento conceitual envolve uma enorme expansão das formas resultantes da atividade cognitiva. Uma pessoa capaz de pensamento abstrato reflete o mundo externo mais profunda e completamente e chega a conclusões e inferências a respeito do fenômeno percebido, tomando por base não só a sua experiência pessoal, mas também os esquemas de pensamento lógico que objetivamente se formam em um estágio avançado do desenvolvimento da atividade cognitiva. (Luria, 1990, p. 135)

Quão longe estão essas idéias defendidas por Luria daquelas defendidas por Schön! Quão opostas são as concepções de Schön e de 
Luria no que diz respeito ao valor do saber escolar, do saber teórico, abstrato, racional! Quão opostos são pressupostos epistemológicos de Donald Schön com relação aos pressupostos epistemológicos marxistas de Luria e Vigotski! E aqui chegamos à explicação de por que Donald Schön não entendeu Luria, por que o autor norte-americano não se deu conta de que o psicólogo soviético defendia exatamente uma posição oposta à sua. A resposta está no fato de que Schön extraiu da pesquisa de Luria um exemplo, sem contextualizar esse exemplo no conjunto dos pressupostos teórico-filosóficos da pesquisa realizada por Luria. Os pressupostos epistemológicos de Schön estão enraizados no pragmatismo de John Dewey, diferentemente dos pressupostos epistemológicos da pesquisa de Luria e Vigotski, os quais estão enraizados no marxismo. E, como mostrou George Novack (1978), em seu livro Pragmatism versus Marxism, há um conflito insuperável entre essas duas correntes filosóficas. Não se dando conta desse conflito, Schön não se deu conta da utilização indevida que fez da pesquisa de Luria.

Concluindo este artigo, esclareço que, ao chamar a atenção para o equívoco de Schön, meu intuito não é o de desqualificar esse autor, mas sim o de alertar para a necessidade de análises rigorosas dos fundamentos filosóficos dos autores que vêm sendo largamente adotados pela intelectualidade da educação brasileira. Já é tempo de reagirmos ao "recuo da teoria", de unirmos os esforços de todos os que não se resignaram perante a passageira hegemonia do ceticismo pós-moderno e do pragmatismo neoliberal.

Recebido em dezembro de 2002 e aprovado em abril de 2003.

\section{Notas}

1. Contei com apoio do CNPq, durante o período de agosto de 1998 a julho de 2002, para desenvolvimento de pesquisa intitulada "O construtivismo: suas muitas faces, suas filiaçốes e suas interfaces com outros modismos".

2. Sobre as aproximações entre as políticas neoliberais no campo da formação de professores e os estudos sobre professor reflexivo, vide o texto de Alessandra Arce (2001), publicado no mesmo número da revista Educação \& Sociedade em que foi publicado o citado artigo de Isabel Alice Lelis.

3. "This reflection-in-action is tacit and spontaneous and often delivered without taking thought, and is not a particularly intellectual activity" (Schön, 1987).

4. Vigotski não pôde realizar com Luria o trabalho de campo, pela fragilidade de sua condição física em consequiência da tuberculose que o acometeu.

Educ. Soc., Campinas, vol. 24, n. 83, p. 601-625, agosto 2003 


\section{Referências bibliográficas}

ARCE, A. Compre o kit neoliberal para a educação infantil e ganhe grátis os dez passos para se tornar um professor reflexivo. Educação \& Sociedade, Campinas, v. 22, n. 74, p. 251-283, 2001.

DUARTE, N. Concepçóes afirmativas e negativas sobre o ato de ensinar. Cadernos Cedes, Campinas, n. 44, p. 85-106, 1998.

DUARTE, N. As pedagogias do "aprender a aprender" e algumas ilusóes da assim chamada sociedade do conhecimento. Revista Brasileira de Educação, Belo Horizonte, n. 18, p. 35-40, 2001a.

DUARTE, N. Vigotski e o "aprender a aprender": crítica às apropriações neoliberais e pós-modernas da teoria vigotskiana. $2^{\text {a }}$ ed. Campinas: Autores Associados, 2001b.

KINCHELOE, J.L. A formação do professor como compromisso politico. Porto Alegre: Artes Médicas, 1997.

KOSIK, K. Dialética do concreto. 2a ed. Rio de Janeiro: Paz \& Terra, 1976.

LELIS, I.A. Do ensino de conteúdos aos saberes do professor: mudança de idioma pedagógico? Educação \& Sociedade, Campinas, v. 22, n. 74, p. 43-58, 2001.

LURIA, A.R. Diferenças culturais de pensamento. In: VIGOTSKI, L.S.; LuRIA, A.R.; Leontiev, A.N. Linguagem, desenvolvimento e aprendizagem. São Paulo: Ícone; EDUSP, 1988.

LURIA, A.R. Desenvolvimento cognitivo. São Paulo: Ícone, 1990.

MORAES, M.C.M. Recuo da teoria: dilemas na pesquisa em educação. In: INTELECTUAIS, conhecimento e espaço público; anais da $24^{\mathrm{a}}$ Reunião Anual da ANPEd. Caxambú, ANPEd, 2001. CD-ROM.

NOVACK, G. Pragmatism versus marxism: an appraisal of John Dewey's philosophy. 2a ed. New York: Pathfinder, 1978.

NÓVOA, A. (Org.). Os professores e a sua formação. $3^{\text {a }}$ ed. Lisboa: Dom Quixote, 1997.

PÉREZ-GOMEZ, A. O pensamento prático do professor: a formação do professor como profissional reflexivo. In: NóVOA, A. (Org.). Os professores e a sua formação. $3^{\text {a }}$ ed. Lisboa: Dom Quixote, 1997. p. 95-114. 
PERRENOUD, P. Práticas pedagógicas, profissão docente e formação: perspectivas sociológicas. 2a ed. Lisboa: Dom Quixote, 1997.

PERRENOUD, P. Formar professores em contextos sociais em mudança: prática reflexiva e participação crítica. Revista Brasileira de Educação, Belo Horizonte, n. 12, p. 5-19, 1999.

PERRENOUD, P. A prática reflexiva no ofício de professor: profissionalização e razão pedagógica. Porto Alegre: Artes Médicas, 2002.

POPKEWITZ, T.S. Profissionalização e formação de professores: algumas notas sobre a sua história, ideologia e potencial. In: NóvoA, A. (Org.). Os professores e a sua formação. $3^{\text {a }}$ ed. Lisboa: Dom Quixote, 1997. p. 37-50.

SCHÖN, D. Educating the reflective practitioner; Donald Schön's presentation to the 1987 meeting of the American Educational Research Association. Washington, DC, 1987. Disponível em: <http://educ.queensu.ca/ russellt/howteach/schon87.htm.> Acesso em: 2003.

SCHÖN, D. Formar professores como profissionais reflexivos. In: Nóvoa, A. (Org.). Os professores e a sua formação. 3. ed. Lisboa: Dom Quixote, 1997. p. 79-91.

SCHÖN, D. Educando o profissional reflexivo: um novo design para o ensino e a aprendizagem. Porto Alegre: Artes Médicas, 2000.

TARDIF, M. Saberes profissionais dos professores e conhecimentos universitários: elementos para uma epistemologia da prática profissional dos professores e suas conseqüências em relação à formação para o magistério. Revista Brasileira de Educação, Belo Horizonte, n. 13, p. 5-24, 2000. 